\title{
The Impact of Admission Red Cell Distribution Width on Myocardial Perfusion and Short-Term Prognosis after Primary Percutaneous Coronary Intervention
}

\author{
M.Oraby, S.Ammar, M.Hamouda, S.Fawzy and R.Ghanoum \\ Cardiology Dept., Faculty of Medicine, Benha univ., Benha, Egypt \\ E-Mail: dr.moh.oraby@gmail.com
}

\begin{abstract}
RDW is a marker of the variability in erythrocyte Vol.ume and is a routinely available component of the complete blood count. Clinical usage of RDW has usually been restricted to differential diagnosis of anemia. However, elevated RDW levels are associated with poor prognoses in acute myocardial infarctions (MI) heart failures stable angina in patients undergoing PCI and general population even in the adjustment for multiple potential confounders, including anemia.The aim of this study is to evaluate the predictive value of red cell distribution width (RDW) on the electrocardiographic and angiographic no-reflow phenomenon in patients undergoing primary percutaneous coronary intervention (PCI).A total of 72 patients were included in this prospective cohort study. The study population was divided into two groups • Group (I): 54 patients with post-procedure ST-T resolution $\geq 50 \%$. Group (II): 18 patients with post-procedure ST-T resolution $<50 \%$. Results of the current study showed that there was significant difference between the 2 groups regarding RDW $(\mathrm{P}=0.003)$, LV systolic function $(\mathrm{P}=0.040)$, TIMI flow after $\mathrm{PPCI}(\mathrm{P}=0.006)$ and $\mathrm{MBG}$ post $\mathrm{PCI}(\mathrm{P}=0.002)$. Also there was significant difference regarding in-hospital MACE $(\mathrm{P}=0.023)$. Cut-off value for RDW as a predictor of outcome was $\geq 14.3 \%$ with accuracy of $68 \%$ i.e. the higher the RDW the worse outcome result should be predicted out of PCI results. So, more focused care should be delivered to patients presented with STEMI and high RDW value.
\end{abstract}

Key words: Red cell distribution width, ST elevation myocardial infarction.

\section{Introduction}

Primary percutaneous coronary intervention (PPCI) is the gold standard of treatment of ST segment elevation myocardial infarction (STEMI) [1]. Primary PCI restores thrombolysis in myocardial infarction flow 3 (TIMI 3) in over $90 \%$ of patients [2]. However there remain a small proportion of patients, who continue to exhibit overt impairment of myocardial reperfusion despite successful opening of infarct related epicardial artery (IRA).

Several recent studies have investigated clinical predictors of no reflow in patients with STEMI treated with primary PCI. White blood cell (WBC) count, thrombus grade/score, age $\geq 60$ years, mean platelet Vol.ume (MPV), duration between onset of chest pain and PCI ( $\geq 4 \mathrm{~h}$ ), hyperglycaemia and raised serum creatinine were a few predictors.

Red cell distribution width (RDW) is a measure of the variability in the size of circulating erythrocytes (anisocytosis), and it has been utilized in the differential diagnosis of anemia [3].

Elevated RDW levels have a close relationship with inflammation and oxidative stress and are associated with poor prognoses in acute and chronic cardiac conditions.

In humans, predictive factors of no-reflow are still poorly understood. Given that the mechanism of increased RDW and pathogenesis of no-reflow might be similar, we hypothesized that increased RDW would be associated with the presence of electrocardiographic no-reflow.

\section{Patients and methods}

This retrospective study was carried out in cardiology department, Benha University and National Heart Institute hospital in Cairo from January 2016 to December 2016. During this period, emergency cardiac catheterization was performed to 72 patients admitted with first acute STEMI. Approval of ethical committee was obtained. Informed consent was obtained from every patient on participation in the study.

\subsection{Inclusion criteria}

Patients who presented with acute ST-T elevation myocardial infraction of $\leq 12 \mathrm{~h}$ duration.

Acute myocardial infarction was defined as new ST elevation of $>1 \mathrm{~mm}$ in at least 2 consecutive leads, presumed new onset left bundle branch block (LBBB) or pathological $\mathrm{Q}$ waves associated with symptoms of ischemia.

Those with age from 33-76 years old in both sexes were included in the study.

\subsection{Statistical analysis}

Data were analyzed using Statistical Program for Social Science (SPSS) version 25.0 for windows (SPSS Inc., Chicago, IL, USA) and NCSS 12.0 for windows (NCSS LCC., Kaysville, UT, USA).

Quantitative data were expressed as mean \pm standard deviation (SD). Median and inter-quartile range (IQR) were also calculated for quantitative data. Qualitative data were expressed as frequency and percentage. 


\section{Results and discussion}

This study was carried out in cardiology department, Benha University and National Heart Institute hospital in Cairo from January 2016 to December 2016. During this period, emergency cardiac catheterization was performed to 72 patients admitted with first acute STEMI. Informed consent was obtained from every patient on participation in the study.

The mean age of the patients was $55.3 \pm 10.2$ years, $52(72.2 \%)$ patients were males and $20(27.8 \%)$ were females, $37(51.5 \%)$ patients were current smokers, $19(26.4 \%)$ patients were diabetic, 28 $(38.9 \%)$ patients were hypertensive, 13 (18.1\%) patients had hypercholesterolemia, $27(37.5 \%)$ patients with positive family history of CAD.

The patients were subdivided according to with ST$\mathrm{T}$ resolution and angiographic evidence of successful reperfusion into 2 subgroups:

- Group (I): 54 patients (75\%) with post-procedure ST-T resolution $\geq 50 \%$.
- Group (II): 18 patients (25\%) with post-procedure ST-T resolution $<50 \%$.

In our study our objective was to evaluate the predictive value of red cell distribution width (RDW) on the electrocardiographic and angiographic noreflow phenomenon in patients undergoing primary percutaneous coronary intervention (PCI).

\subsection{Echo outcome in both groups}

- Group (I): Mean EF\% was $49.3 \pm 9.2$ post PCI

- Group (II): Mean EF\% was $44.2 \pm 7.9$ post PCI while ST-T resolution percentage median was 32.5 $(20-40) \%$.

There was a significant statistical difference between the two groups regarding the left ventricular function by Echo ( $\mathrm{p}$ value $=0.040$ ) and highly significant statistical difference regarding ST-T resolution percentage ( $\mathrm{p}$ value $<0.001$ ) Table (1).

Table (1) Comparison between the studied groups regarding the post 1ry PCI data.

\begin{tabular}{|c|c|c|c|c|}
\hline \multicolumn{5}{|l|}{ Groups } \\
\hline Post 1ry PCI data & $\begin{array}{c}\text { Successful } \\
\text { reperfusion }\end{array}$ & Failed reperfusion & Test & P-value (Sig.) \\
\hline Count & 54 & 18 & & \\
\hline $\begin{array}{l}\text { STR }(\mathbf{m m}) \\
\text { Median (IQR) } \\
\text { LVEF }(\%)\end{array}$ & $65(60-71)$ & $32.5(20-40)$ & $6.364 \bullet$ & $<0.001$ (HS) \\
\hline Mean \pm SD & $49.3 \pm 9.2$ & $44.2 \pm 7.9$ & $2.091 *$ & $0.40 \quad(\mathrm{~S})$ \\
\hline
\end{tabular}

3.2 Angiographic results

\subsubsection{Final TIMI flow}

- Group (I) The final TIMI flow was $\geq 2$ in $51(94.4 \%)$ patients, while TIMI flow was < 2 in $3(5.6 \%)$ patients.

- Group (II) The final TIMI flow was $\geq 2$ in $12(66.7 \%)$ patients, while TIMI flow was < 2 in $6(33.3 \%)$ patients.

There was significant statistical difference between the two groups regarding the final TIMI flow. (P value $=0.006)$ Table (2).

Myocardial blush grade (MBG)

Group (I) The final MBG was $\geq 2$ in 49 $(90.7 \%)$ patients, while $\mathrm{MBG}$ was $<2$ in 5 $(9.3 \%)$ patients.

Group (II) The final $\mathrm{MBG}$ was $\geq 2$ in 10 (55.6\%) patients, while MBG was $<2$ in 8 $(44.4 \%)$ patients.

There was significant statistical difference between the two groups regarding the final MBG. (P value =0.002), Table (2) Fig (1).

\subsection{The major events during hospital stay}

- Group (I) Two patients (3.7\%) had non-fatal myocardial infarction, 2 patients $(3.7 \%)$ had non-fatal stroke and one patient $(1.9 \%)$ had cardiovascular death.

- Group (II) Four patients (22.2\%) had nonfatal myocardial infarction, one patient $(5.6 \%)$ had non-fatal stroke and one patient $(5.6 \%)$ had cardiovascular death.

There was significant statistical difference between the two groups regarding non-fatal myocardial infarction during hospital stay. ( $\mathrm{P}$ value $=0.031$ ) Table (3), Fig (2).

Multivariate regression analysis of the predictors of for incidence of reperfusion failure showed that elevated RDW level was the most significant predictor $(\mathrm{P}$ value $=$ 0.003).

Univariate analysis for the role of elevated RDW level, it was found to be associated with increase in the relative risk ratio of reperfusion failure, $\mathrm{P}=0.007$ ).

Measurement of RDW has an important role for early risk stratification in patients with STEMI. 
RDW cut-off value upon which there was higher risk of reperfusion failure was $14.3 \%$ with $95 \%$ sensitivity and $95 \%$ specificity. Table (4) Fig (3)
According to this statistical analysis, enrolled patients' RDW cut-off value upon which there was higher risk of reperfusion failure was $14.3 \%$ with $95 \%$ sensitivity and $95 \%$ specificity.Table $(5,6)$

Table (2) Comparison between the studied groups regarding the 1ry PCI data.

\begin{tabular}{|c|c|c|c|c|}
\hline Groups & & & & \\
\hline 1ry PCI data & Successful reperfusion & Failed reperfusion & Test & P-value \\
\hline Count & 54 & 18 & & (Sig.) \\
\hline DTB (min) & & & & \\
\hline Median (IQR) & $57.5(45-71)$ & $60(40-70)$ & $-0.868 \bullet$ & $0.385(\mathrm{NS})$ \\
\hline Target vessel (culprit) & & & & \\
\hline LAD & $39(72.2 \%)$ & $14(77.8 \%)$ & $0.754 \$$ & $0.686(\mathrm{NS})$ \\
\hline LCX & $7(13 \%)$ & $1(5.6 \%)$ & & \\
\hline RCA & $8(14.8 \%)$ & $3(16.7 \%)$ & & \\
\hline Number of vessels affe & & & & \\
\hline Single or two vessels & $43(79.6 \%)$ & $15(83.3 \%)$ & $t^{\mathrm{F}}$ & $1.000(\mathrm{NS})$ \\
\hline Multi-vessels & $11(20.4 \%)$ & $3(16.7 \%)$ & & \\
\hline Other vessels affected & & & & \\
\hline LAD & $10(18.5 \%)$ & $2(11.1 \%)$ & $t^{\mathrm{F}}$ & $0.718(\mathrm{NS})$ \\
\hline LCX & $20(37 \%)$ & $7(38.9 \%)$ & $0.020 \$$ & 0.888 (NS) \\
\hline RCA & $20(37 \%)$ & $5(27.8 \%)$ & $0.511+$ & 0.475 (NS) \\
\hline Ramus & $2(3.7 \%)$ & $2(11.1 \%)$ & $t^{\mathrm{F}}$ & 0.259 (NS) \\
\hline TIMI flow post PCI & & & & \\
\hline TIMI $<2$ & $3(5.6 \%)$ & $6(33.3 \%)$ & $t^{\mathrm{F}}$ & $0.006(\mathrm{~S})$ \\
\hline TIMI $\geq 2$ & $51(94.4 \%)$ & $12(66.7 \%)$ & & \\
\hline MBG post PCI & & & & \\
\hline $\mathrm{MBG}<2$ & $5(9.3 \%)$ & $8(44.4 \%)$ & $t^{F}$ & $0.002(\mathrm{~S})$ \\
\hline$M B G \geq 2$ & $49(90.7 \%)$ & $10(55.6 \%)$ & & \\
\hline
\end{tabular}

- Mann Whitney U test. † Chi-square test. $\dagger^{\mathbf{F}}$ Fisher's Exact test. $\mathrm{p}<0.05$ is significant.

Sig.: significance.

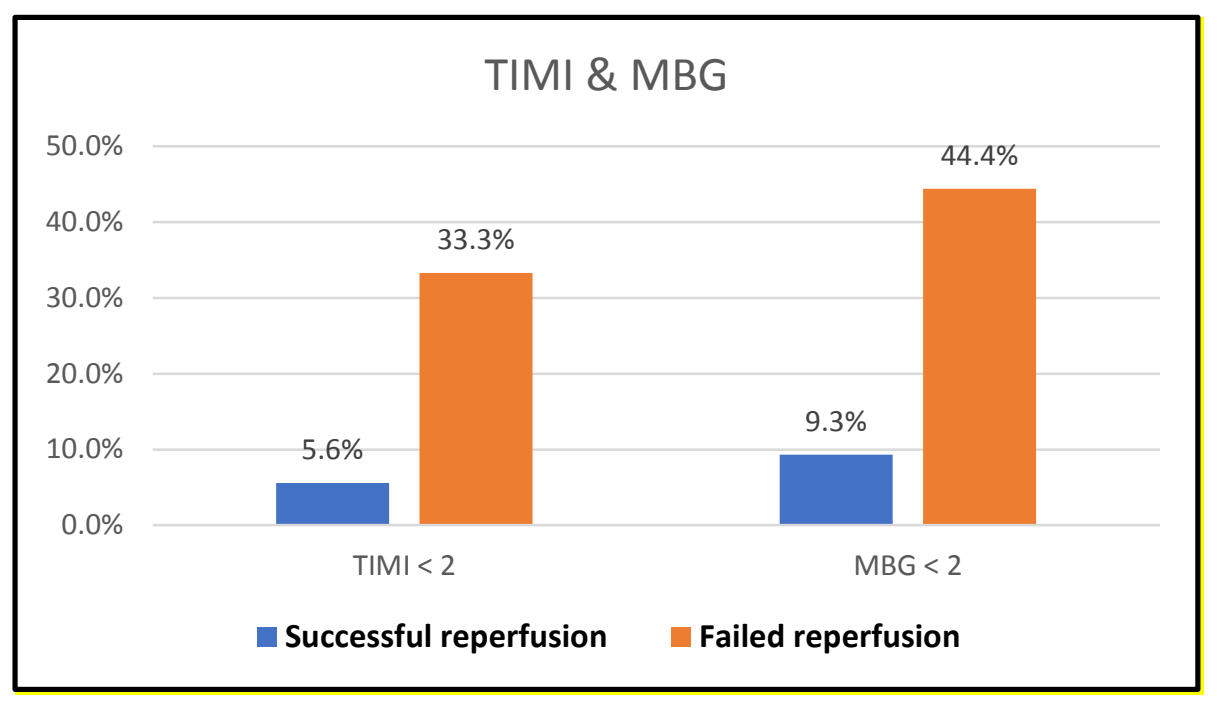

Fig (1) TIMI flow and MBG of both groups I and II 
Table (3) Comparison between the studied groups regarding the short-term (in-hospital) outcomes (MACEs).

\begin{tabular}{|c|c|c|c|c|}
\hline \multicolumn{5}{|l|}{ Groups } \\
\hline $\begin{array}{l}\text { In-hospital } \\
\text { (MACEs) }\end{array}$ & sful reperfusion & Failed reperfusion & \multirow[t]{2}{*}{ Test } & \multirow[t]{2}{*}{$\begin{array}{l}\text { P-value } \\
\text { (Sig.) }\end{array}$} \\
\hline Count & 54 & 18 & & \\
\hline \multicolumn{5}{|l|}{ Outcomes } \\
\hline Composite endpoint & $5(9.3 \%)$ & $6(33.3 \%)$ & & $0.023(\mathrm{~S})$ \\
\hline Non-fatal MI & $2(3.7 \%)$ & $4(22.2 \%)$ & & $0.031(\mathrm{~S})$ \\
\hline Non-fatal stroke & $2(3.7 \%)$ & $1(5.6 \%)$ & & $1.000(\mathrm{NS})$ \\
\hline Cardiovascular death & $1(1.9 \%)$ & $1(5.6 \%)$ & & 0.440 (NS) \\
\hline
\end{tabular}

† Chi-square test. $\quad{ }^{\mathbf{F}}$ Fisher’s Exact test. $\mathrm{p}<0.05$ is significant. Sig.: significance.

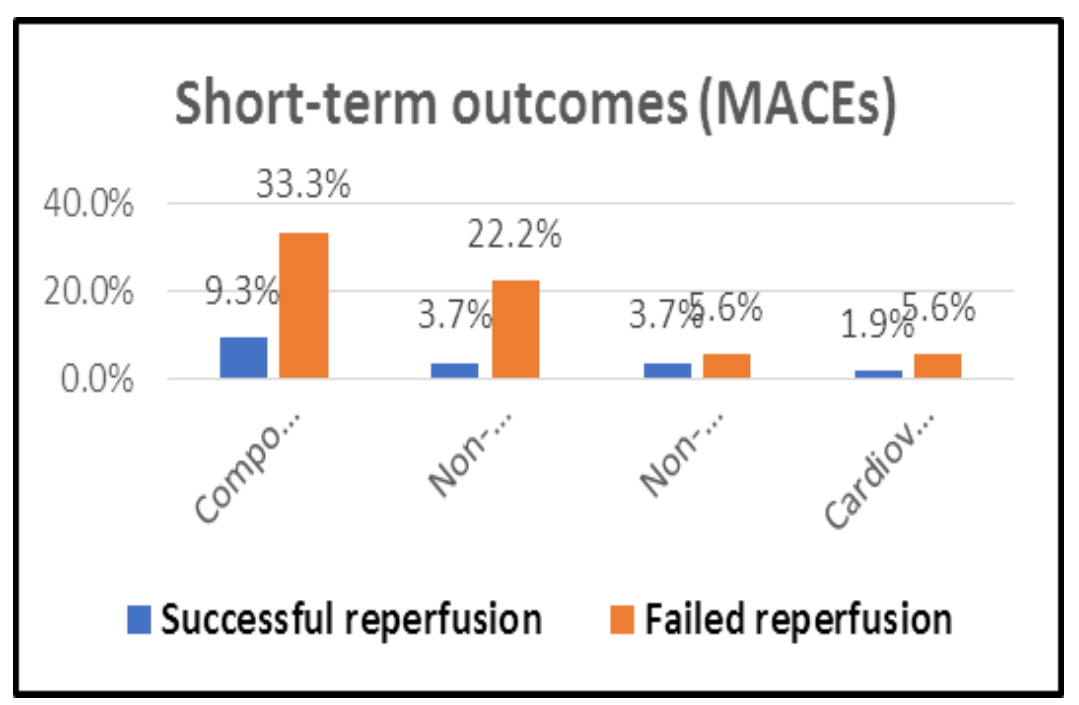

Fig (2) Major events during in-hospital stay of both groups I and II

Table (4) Univariate regression analysis for incidence of reperfusion failure.

\begin{tabular}{|c|c|c|c|c|}
\hline \multicolumn{5}{|l|}{ Groups } \\
\hline \multirow[t]{2}{*}{ Variable } & \multirow[t]{2}{*}{$\begin{array}{c}\text { Unadjusted } \\
\text { OR }\end{array}$} & \multicolumn{2}{|c|}{$\begin{array}{l}\text { 95\% Confidence Interval for } \\
\text { OR }\end{array}$} & \multirow[t]{2}{*}{$\begin{array}{c}\text { P-value } \\
\text { (Sig.) }\end{array}$} \\
\hline & & Lower Bound & Upper Bound & \\
\hline RDW (\%) & 2.664 & 1.395 & 5.089 & 0.003 \\
\hline TIMI $<2$ & 8.500 & 1.856 & 38.938 & 0.006 \\
\hline MBG $<2$ & 7.840 & 2.120 & 29.000 & 0.002 \\
\hline
\end{tabular}

Table (5) Multivariate regression analysis for incidence of reperfusion failure.

\begin{tabular}{|c|c|c|c|c|}
\hline \multicolumn{5}{|l|}{ Groups } \\
\hline \multirow[t]{3}{*}{ Variable } & \multirow[t]{3}{*}{ Adjusted OR } & \multirow{2}{*}{\multicolumn{2}{|c|}{$\begin{array}{l}\text { 95\% Confidence Interval for } \\
\text { OR }\end{array}$}} & \multirow{3}{*}{$\begin{array}{c}\text { P-value } \\
\text { (Sig.) }\end{array}$} \\
\hline & & & & \\
\hline & & Lower Bound & Upper Bound & \\
\hline RDW (\%) & 2.688 & 1.314 & 5.498 & 0.007 \\
\hline TIMI $<2$ & 5.154 & 0.561 & 47.357 & 0.147 \\
\hline MBG $<2$ & 2.425 & 0.393 & 14.959 & 0.340 \\
\hline
\end{tabular}


Table (6) The cut-off value of RDW (\%) for incidence of reperfusion failure; ROC curve analysis

\begin{tabular}{|c|c|c|c|c|c|c|c|}
\hline Groups & & & & & & & \\
\hline $\begin{array}{l}\text { Cut-off } \\
\text { value }\end{array}$ & $\begin{array}{c}\text { SN \% } \\
(95 \% \text { CI })\end{array}$ & $\begin{array}{c}\text { SP \% } \\
(95 \% \text { CI })\end{array}$ & $\begin{array}{l}\text { PPV \% } \\
(95 \% \text { CI })\end{array}$ & $\begin{array}{l}\text { NPV \% } \\
(95 \% \text { CI) }\end{array}$ & $\begin{array}{c}\text { Accuracy } \\
\% \\
(95 \% \text { CI }) \\
\end{array}$ & $\begin{array}{c}\text { AUROC } \\
(95 \% \text { CI })\end{array}$ & $\begin{array}{c}\text { P-value } \\
\text { (Sig.) }\end{array}$ \\
\hline $\begin{array}{l}\text { RDW } \\
14.3 \%\end{array}$ & $\begin{array}{c}72.2 \% \\
(46.5-90.3)\end{array}$ & $\begin{array}{c}66.7 \% \\
(52.5-78.9)\end{array}$ & $\begin{array}{c}41.9 \% \\
(24.6-60.9)\end{array}$ & $\begin{array}{c}87.8 \% \\
(73.8-95.9)\end{array}$ & $\begin{array}{c}68.1 \% \\
(56.0-78.6)\end{array}$ & $\begin{array}{c}0.751 \\
(0.596-0.852)\end{array}$ & $\begin{array}{c}<0.001 \\
(\mathrm{HS})\end{array}$ \\
\hline
\end{tabular}

ROC curve: Receiver Operating Characteristic curve.

SN: Sensitivity.

SP: Specificity.

PPV: Positive Predictive Value.

NPV: Negative Predictive Value.
AUROC: Area Under Receiver Operating Characteristic curve.

95\%CI: 95\% Confidence Interval. $\mathrm{p}<0.05$ is significant. Sig.: significance.

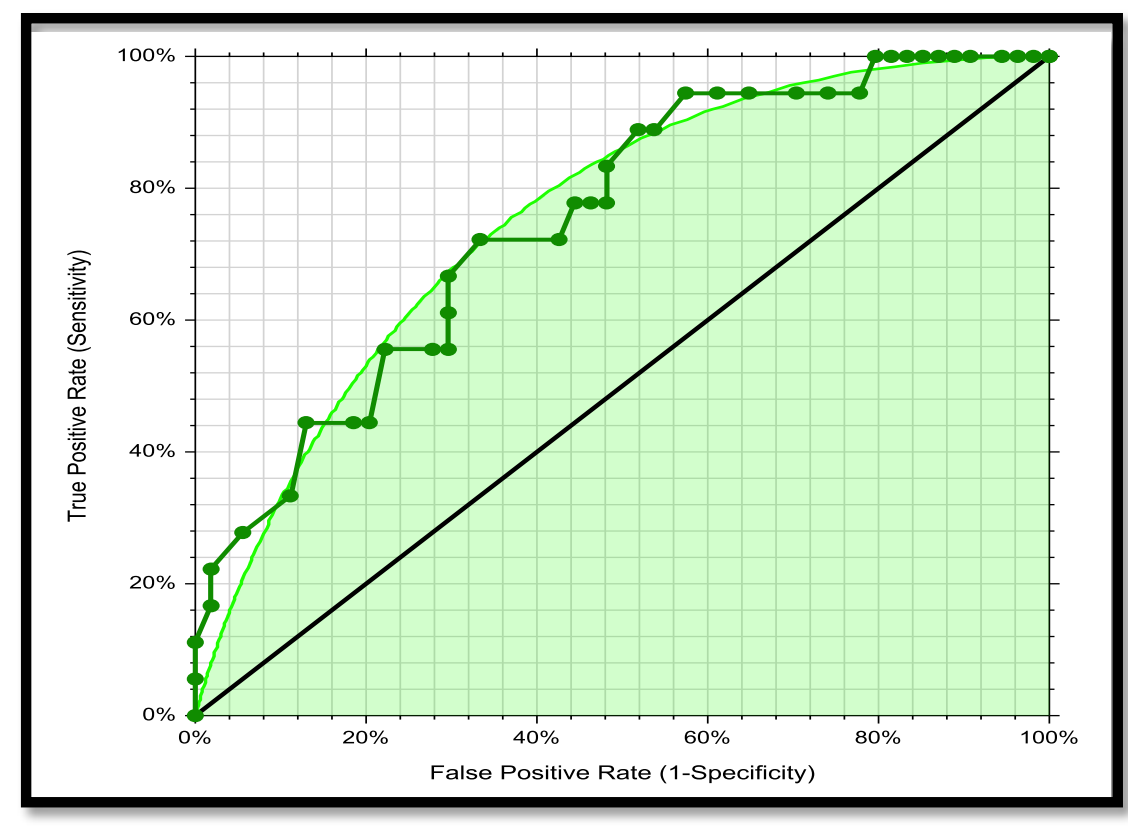

Fig (3) ROC curve analysis for RDW (\%) in prediction of reperfusion failure.

\section{Discussion}

Results of the current study showed that there was significant difference between the 2 groups regarding the TIMI flow after PPCI $(\mathrm{P}=0.013)$. But no significant difference was found between two groups regarding ECG signs of failure, $\mathrm{MBG}$ and $\mathrm{MACE}(\mathrm{P}=$ $0.89, \quad \mathrm{P}=0.97$, respectively $\mathrm{P}=0.38$ for instent thrombosis, $\mathrm{P}=0.21$ for myocardial infarction and $\mathrm{P}=0.21$ for death).

According to this statistical analysis, enrolled patients' RDW cut-off value upon which there was higher risk of reperfusion failure was $14.3 \%$ with 95\% sensitivity and $95 \%$ specificity.

Results of this study are in concordance with previous study [4] that included 370 patients who presented to hospital with acute myocardial infarction (Group 1: 198 young patients, $<45$ ages for male, < 55 ages for female, Group 2: 172 elderly patients) and 156 adults with normal coronary angiography as a control group (Group 3: 91 young patients, < 45 ages for 
male, < 55 ages for female, Group 4: 65 elderly patients). High levels of RDW were associated with STEMI in young patients. They think that RDW is a widely available marker with no additional costs, in contrast to other novel markers of cardiovascular risk.

Our results agreed with previous study [5] who studied relationship between red cell distribution width and complication risk in patients with acute myocardial infarction. From January 2006 to December 2009, 200 consecutive AMI patients admitted in cardiology department of affiliated hospital of putian university were enrolled. Patients were classified into complication group $(n=145)$ or complication-free group $(n=55)$ according to the presence or absence of new-onset symptomatic heart failure, arrhythmia or cardiac shock. Correlation of RDW with NT-proBNP, cTnI and hs-CRP was compared by spearman rank correlation analysis. Higher RDW is closely associated with increased risk of AMI complication and elevated plasma NT-proBNP and cTnI level.

Our results agreed also with previous study [6] in which the baseline characteristics, including RDW, were collected for 25612 participants in the Troms $\varnothing$ Study in 1994-1995. Incident MI during follow-up was registered from inclusion through December 31, 2010. Cox regression models were used to calculate hazard ratios with $95 \%$ confidence intervals for MI, adjusted for age, sex, body mass index, smoking, hemoglobin, white blood cells, platelets, and other traditional cardiovascular risk factors. A total of 1779 participants experienced a first-ever MI during a median follow-up time of 15.8 years. There was a linear association between RDW and risk of MI, for which a $1 \%$ increment in RDW was associated with a $13 \%$ increased risk (hazard ratio 1.13; 95\% CI, 1.07 to 1.19). Participants with RDW above the 95th percentile had $71 \%$ higher risk of MI compared with those with RDW in the lowest quintile (hazard ratio $1.71 ; 95 \%$ CI, 1.34 to 2.20). All effect estimates were essentially similar after exclusion of participants with anemia $(n=1297)$ from the analyses. RDW is associated with incident $\mathrm{MI}$ in a general population independent of anemia and cardiovascular risk factors.

Also, our study matches with a study done on patients with acute coronary syndromes by previous study [7] which analyzed blood parameters in 251 adult patients who were consecutively admitted to the intensive coronary care unit with non-ST-elevation acute coronary syndrome over a 1-year period. For all patients, a baseline blood sample was collected for routine hematological testing. Cardiac troponin I was measured at baseline and after 6 h. The patients were diagnosed with non-ST-elevation myocardial infarction or unstable angina based on the elevation of cardiac troponin I levels. A greater baseline red cell distribution width value was associated with myocardial injury and elevated cardiac troponin I levels in non-ST-elevation acute coronary syndrome. Therefore, the red cell distribution width could be considered for risk stratification of acute coronary syndrome patients admitted to emergency departments.

Also a previous study [8] who determined red cell and platelet distribution widths retrospectively in 46 patients with stable angina pectoris and 140 patients with acute myocardial infarction who were brought to the emergency department of their institution. Red cell and platelet distribution widths were determined with an automatic blood cell analyzer, and the results were compared between the acute myocardial infarction and angina pectoris groups. In this study, PDW values were higher in the AMI group than in the AP group before and at onset. Red cell distribution widths and especially platelet distribution widths may contribute to the early detection of acute myocardial infarction.

\section{Conclusions}

This study was done to find out the prognostic value of red cell distribution width among patients with ST segment elevated MI (STEMI) and its correlation with in-hospital prognosis.

RDW levels were significantly higher among patients with successful reperfusion according to ST-T resolution after primary PCI with mean RDW 
value $13.7 \pm 1.1$ than those failed reperfusion as the mean RDW value $14.7 \pm 0.9(\mathrm{P}=0.001)$.

RDW levels were significantly higher among patients with in-hospital complications than those without inhospital complications as the mean $(\mathrm{P}=$ $0.023)$.

The adverse cardiovascular events in hospital occurred in 11 patients $(15.3 \%)$ Death occurred in 2 patients $(2.8 \%)$, non-fatal MI in 6 patients $(8.3 \%)$ and cerebrovascular stroke in 3 patients $(4.2 \%)$.

Multivariate regression analysis of the predictors of for incidence of reperfusion failure showed that elevated RDW level was the most significant predictor $(\mathrm{P}$ value $=0.003$ )

Univariate analysis for the role of elevated RDW level, it was found to be associated with increase in the relative risk ratio of reperfusion failure, $\mathrm{P}=$ 0.007).

RDW cut-off value upon which there was higher risk of reperfusion failure was $14.3 \%$ with $95 \%$ sensitivity and $95 \%$ specificity.

\section{References}

[1] P. T O'Gara., F. G Kushner,., D. D Ascheim,., D. E Casey, M. K Chung., J. A De Lemos \& C. B. Granger, ACCF/AHA guideline for the management of STelevation myocardial infarction: executive summary: a report of the American College of Cardiology Foundation/American Heart Association Task Force on Practice Guidelines. Journal of the American College of Cardiology, Vol. 61(4), PP. 485-510. 2013.

[2] G. W.Stone, , M. A Peterson,., A. J Lansky,.., G Dangas,., R Mehran,., \& , M. B Leon. Impact of normalized myocardial perfusion after successful angioplasty in acute myocardial infarction. Journal of the American College of Cardiology, Vol. 39(4), PP. 591-597. 2002.
[3] J. B Muhlestein,., D. L Lappe,., J. L Anderson,., J. B Muhlestein,., D Budge,., H. T May,.., ... \&, B. D Horne. Both initial red cell distribution width (RDW) and change in RDW during heart failure hospitalization are associated with length of hospital stay and 30-day outcomes. International journal of laboratory hematology, Vol. 38(3), PP. 328-337. 2016.

[4] P.Wang, , Y.Wang, , H.Li, , Y Wu,.., \& H.Chen, Relationship between the red blood cell distribution width and risk of acute myocardial infarction. Journal of atherosclerosis and thrombosis, Vol. 23937. 2014.

[5] K Xu,., L Lin,., J.Lin, , J. Zheng, , \& D Cai,. e0463 Relationship between red cell distribution width and complication risk in patients with acute myocardial infarction. Heart, Vol. 96(Suppl 3), PP. A144-A144. 2010.

[6] T. S Ellingsen,., J Lappegård,., T.Skjelbakken, , S. K., Brækkan, \& J. B Hansen,. Impact of red cell distribution width on future risk of cancer and allcause mortality among cancer patients-the Troms $\varnothing \quad$ Study. haematologica, Vol. 100(10),PP. e387. 2015.

[7] A. R.Tosu, , S.Demir, , M.Selcuk, , Y.Kaya, , A.Akyol, , M.Ozdemir, , \& E. Tenekecioglu, Comparison of inflammatory markers in non-dipper hypertension vs. dipper hypertension and in normotensive individuals: uric acid, Creactive protein and red blood cell distribution width readings. Postępy w Kardiologii Interwencyjnej= Advances in Interventional Cardiology, Vol.. 10(2), PP. 98. 2014

[8] M.Terakura, , T.Sugawara, , D.Hirota, , T.Sagawa, , \& T.Sakamoto, Red cell and platelet distribution widths in patients with angina pectoris and acute myocardial infarction. Acute medicine \& surgery, Vol.. 3(3), PP. 244-249. 2016. 